\title{
The shape of the glucose response curve during an oral glucose tolerance test heralds $\beta$-cell function in a large Chinese population
}

Xinqi Cheng ${ }^{1+}$, Na Yang ${ }^{2 \dagger}$, Yuxiu Li ${ }^{2}$, Qi Sun ${ }^{2}$, Ling Qiu' ${ }^{1}$ Lingling Xu ${ }^{2}$ Fan Ping ${ }^{2}$, Wei Li ${ }^{2}$ and Huabing Zhang ${ }^{2^{*}}$ (D)

\begin{abstract}
Background: The shape of the glucose response curve during an oral glucose tolerance test (OGTT) can predict $\beta$ cell function and insulin resistance. However, there have been few studies conducted on Chinese people. Thus, we aimed to verify the usefulness of the glucose response curve in a large Chinese population.

Methods: A total of 9059 OGTT (3-h tests) were categorized into either a monophasic or a multiphasic group based on the shape of the glucose response. Homeostasis model assessments of fasting insulin resistance, the Matsuda Index, the insulinogenic index, and the disposition index were assessed by plasma glucose and serum insulin concentration obtained at fasting or during an OGTT.

Results: The shape of the OGTT glucose response curve was monophasic in $87.3 \%$ and multiphasic in $12.7 \%$ of participants. Individuals in the multiphasic group were younger compared to those in the monophasic group (38.6 \pm 13.6 vs. $35.4 \pm 13.5, P<0.001$ ). Individuals in the monophasic group had significantly higher fasting plasma glucose (FPG 5.6 \pm 13.5 vs. $5.2 \pm 0.6, P<0.001$ ), fasting insulin (FINS $14.8 \pm 8.7$ vs. $13.5 \pm 7.9, P<0.01$ ), and homeostasis model assessment of insulin resistance (HOMA-IR $3.8 \pm 2.6$ vs. $3.1 \pm 2.0, P<0.001$ ) and impaired $\beta$-cell function (disposition index $12.7 \pm 14.1$ vs. $16.6 \pm 17.8, P<0.001$ ) compared to those in the multiphasic group.
\end{abstract}

Conclusion: The monophasic OGTT glucose response curve could reflect impaired $\beta$-cell function in a large Chinese population.

Keywords: OGTT, Glucose response curve, Chinese

\section{Background}

Diabetes mellitus (DM) has been categorized as a complex and multifactorial metabolic condition [1]. Many factors play important roles in the development of glucose intolerance in individuals with type 2 diabetes (T2D), such as impaired insulin secretion and insulin resistance [2,3]. It is widely accepted that the gold standard method for evaluating insulin action is hyperinsulinemic-euglycemic clamp [4]. Because this method is invasive, complicated, and expensive, its

\footnotetext{
* Correspondence: huabingzhangchn@163.com

${ }^{+}$Xinqi Cheng and Na Yang contributed equally to this work.

${ }^{2}$ Department of Endocrinology, Key Laboratory of Endocrinology, Ministry of Health, Peking Union Medical College Hospital, Chinese Academy of Medical Sciences \& Peking Union Medical College, Beijing, China

Full list of author information is available at the end of the article
}

application in clinical practice is limited. The oral glucose tolerance test (OGTT) has been used to diagnose diabetes or to capture the impaired fasting glucose (IFG) and impaired glucose tolerance (IGT) based on the fasting plasma glucose (FPG) and 2-h plasma glucose (2hPG) [5]. Although $\beta$-cell function and insulin action can be obtained through calculating a series of formulas, such as the insulinogenic index or Matsuda Index during the OGTT, they are not intuitive. The OGTT glucose response curve could be a novel and intuitive biomarker to identify early metabolic risk [6]. Recent crosssectional studies [6-13] showed that OGTT response curves, either monophasic or biphasic, can not only indicate $\beta$-cell function and insulin resistance but also differentiate diabetes risk. Those studies revealed that

(c) The Author(s). 2019 Open Access This article is distributed under the terms of the Creative Commons Attribution 4.0 International License (http://creativecommons.org/licenses/by/4.0/), which permits unrestricted use, distribution, and reproduction in any medium, provided you give appropriate credit to the original author(s) and the source, provide a link to the Creative Commons license, and indicate if changes were made. The Creative Commons Public Domain Dedication waiver (http://creativecommons.org/publicdomain/zero/1.0/) applies to the data made available in this article, unless otherwise stated. 
individuals with a monophasic curve tended to have worse insulin sensitivity and $\beta$-cell function. A recent prospective study demonstrated that individuals with a biphasic curve developed T2D at a lower rate than those with a monophasic curve, independent of FPG and/or 2hPG [14].

However, the scale of these studies was generally small, with a maximum of hundreds of subjects included, and only one study was conducted in an Asian population [11]. These studies mainly focused on people without diabetes. No studies showed a relationship between age and the shape of the glucose response curve. In addition, few studies reported the dynamic change of glucose response curves and their relationship with baseline $\beta$-cell function and insulin sensitivity.

Therefore, the purposes of this study were as follows: 1) to verify the utility of the OGTT glucose response curve in predicting $\beta$-cell function and insulin sensitivity in a large Chinese population with varying statuses of glucose tolerance; 2) to examine the relationship between age and the shape of glucose response curves; and 3) to assess if the shape of glucose response curves changed dynamically over time and whether the change was related to baseline $\beta$-cell function and insulin sensitivity.

\section{Methods}

\section{Subjects}

We retrospectively analyzed data of individuals who were tested with a 3-h OGTT and with complete glucose and insulin testing in Peking Union Medical College Hospital from August 2011 to January 2018. Participants were excluded from the study if any of the following criteria were met: a) missing demographic information (age or sex); b) under 18 years old and over 18 years old who did not receive $75 \mathrm{~g}$ glucose for OGTT; c) FPG <3.9 $\mathrm{mmol} / \mathrm{L}$; d) history of diabetes; e) FINS $>60 \mu \mathrm{IU} / \mathrm{ml}$ or serum insulin level $>300 \mu \mathrm{IU} / \mathrm{ml}$ at any point of OGTT, because the upper limit was $300 \mu \mathrm{IU} / \mathrm{ml}$; e) 30-min plasma glucose $\leq 0$-min plasma glucose or 30 -min serum insulin $\leq 0$-min serum insulin, to ensure insulinogenic index could be calculated; and g) shapes of the curve could not be classified.

\section{Blood sampling and OGTT}

After an overnight fast, participants underwent a 3-h OGTT with the ingestion of $75 \mathrm{~g}$ glucose. Venous blood samples were obtained at $0,30,60,120$, and $180 \mathrm{~min}$. Plasma glucose was measured by the hexokinase method using a Beckman AU2700 analyzer (Beckman Coulter, Brea, CA, USA). Serum insulin was assessed by chemiluminescence immunoassay using a Siemens ADIVA Centaur XP analyzer (Siemens Healthcare Diagnostics Inc., Tarrytown, NY, USA). The glucose and insulin assays were standardized to NIST SRM 965 and WHO 1st IRP
$66 / 304$, respectively. The repeatability and within laboratory coefficient variations were $<5 \%$.

\section{Classification of glucose tolerance status}

According to the World Health Organization definition $[5,15,16]$, normal glucose tolerance (NGT) was defined as $\mathrm{FPG}<6.1 \mathrm{mmol} / \mathrm{L}$ and 2 -h plasma glucose $<7.8$ $\mathrm{mmol} / \mathrm{L}$. Prediabetes was defined as having IFG (FPG: 6.1-6.9 mmol/L) and/or IGT (2-h plasma glucose: $7.8-$ $11.0 \mathrm{mmol} / \mathrm{L}$ ). Diabetes was defined as having FPG $\geq 7.0$ $\mathrm{mmol} / \mathrm{l}$ and/or 2 -h plasma glucose $\geq 11.1 \mathrm{mmol} / \mathrm{L}$.

\section{Classification of glucose curve shapes}

The shapes were classified in line with previous studies [17]. A monophasic response curve was determined by a gradual increase in glucose concentrations until a peak was reached, followed by a subsequent decrease in glucose of $\geq 0.25 \mathrm{mmol} / \mathrm{L}$. A biphasic response curve was defined by the second rise in glucose concentrations of $\geq 0.25 \mathrm{mmol} / \mathrm{L}$. A triphasic response curve was defined by two complete peaks of the plasma glucose curve, with every rise and decrease in glucose concentrations of $\geq 0.25 \mathrm{mmol} / \mathrm{L}$. The latter two were collectively called multiphasic response curve. This was done with a plasma glucose threshold of $0.25 \mathrm{mmol} / \mathrm{L}$ to minimize fluctuations in glucose concentrations, which may be caused by the method of glucose analysis rather than by physiological reasons.

\section{Calculation of variables}

Areas under the glucose and insulin curves were calculated with the trapezoidal rule [10]. Insulin action was estimated by the homeostasis model assessment for insulin resistance (HOMA-IR) and the whole-body insulin sensitivity index of Matsuda. HOMA-IR $=\left(\mathrm{I}_{0}-\mathrm{G}_{0}\right) / 22.5$, with glucose and insulin expressed as $\mathrm{mmol} / \mathrm{L}$ and $\mathrm{mUI} /$ $\mathrm{ml}$, respectively [18]. The Matsuda Index $=10,000 /$ $\sqrt{ }[($ fasting glucose $(\mathrm{mg} / \mathrm{dl}) \times$ FINS $(\mu \mathrm{U} / \mathrm{ml})) \times($ mean glucose $(\mathrm{mg} / \mathrm{dl}) \times$ mean insulin $(\mu \mathrm{U} / \mathrm{ml})$ ] [19]. Insulin secretion was estimated by the insulinogenic index. The insulinogenic index was calculated using fasting and 30min insulin and glucose concentrations [20]. $\beta$-cell function was estimated by the disposition index as the product of insulinogenic index and HOMA-IR [21].

\section{Statistical analysis}

Summary statistics were calculated using frequencies and proportions for categorical data and means (standard deviations) for continuous variables. Kruskal-Wallis, Pearson $X^{2}$, and unpaired Student's t-tests were used for comparisons. Analysis of covariance was used to compare two glucose response curve groups (monophasic vs. multiphasic) after adjusting for the potential confounding effects (age, sex, glycemic status). A two-sided $p$ - 
value $<0.05$ was considered to indicate statistical significance.

All data were analyzed using IBM SPSS Statistics, version 25. The authors have full access to and take full responsibility for the integrity of the data. The manuscript has been read and approved by all the authors.

\section{Results}

Baseline characteristics according to glucose curve shapes A total of 9059 OGTTs in 8391 study individuals were included in the final analysis (Fig. 1). The baseline age was $38.2 \pm 13.6$ years, and $74.4 \%$ were female. In terms of the shape of the participants' OGTT glucose response curve, $87.3 \%$ were monophasic, $6.1 \%$ were biphasic, and $6.6 \%$ were triphasic. Although the individuals with a triphasic curve had better insulin sensitivity and $\beta$-cell function than those with a biphasic curve (Table 1), in view of the limited cases, the triphasic group and the biphasic group were collectively referred to as the multiphasic group. Physical and glucose metabolic characteristics of participants with monophasic and multiphasic curves are presented in Table 1. Figure 2 illustrates the average glucose

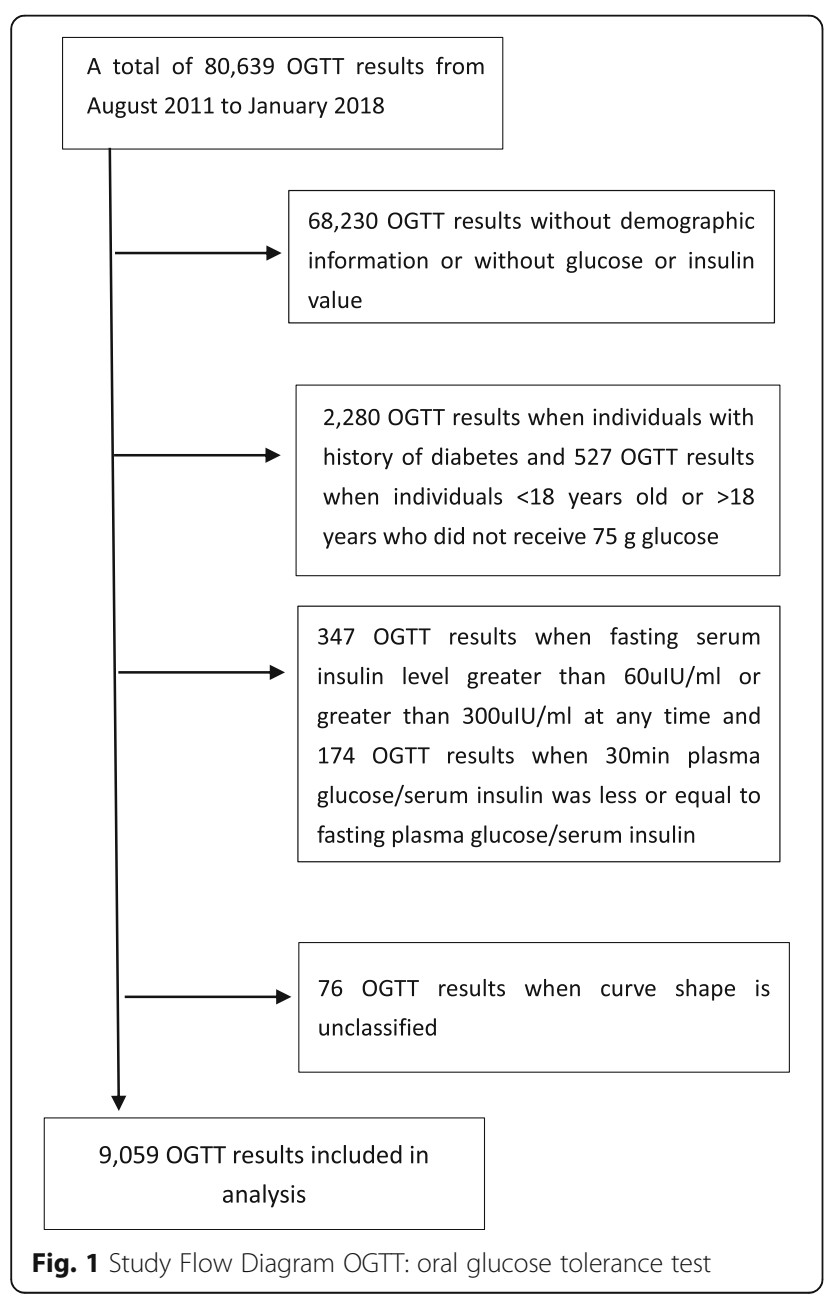

at each point in the monophasic, biphasic, and triphasic curves. The monophasic group exhibited significantly higher FPG (5.6 \pm 13.5 vs. $5.2 \pm 0.6)$, 2 hPG (8.2 \pm 3.2 vs. $6.3 \pm 2.0$ ), fasting serum insulin (FINS), and $2 \mathrm{~h}$ serum insulin ( $2 \mathrm{~h}$ INS) than the multiphasic group. The monophasic group had a significantly higher HOMA-IR (3.8 \pm 2.6 vs. $3.1 \pm 2.0)$ and lower Matsuda Index $(2.9 \pm 1.9$ vs. $3.8 \pm$ $2.5)$ and insulinogenic index $(25.1 \pm 23.0$ vs. $16.6 \pm 17.8)$. Disposition index, the indicator of $\beta$-cell function, was nearly $42 \%$ lower in the monophasic group (Table 1 ). These differences remained significant after adjusting for sex and age.

\section{Comparison of the glucose curve shapes among different age groups}

To explore the relationship between age and the shape of the OGTT curve, we divided age into six categories (Fig. 3). We found that a higher proportion of younger people belonged to the multiphasic group, i.e., a significantly higher proportion of participants aged 18 to 30 years $(16.8 \%)$ were in the multiphasic group compared with all the other, older groups (30-40 years: $12.2 \%$, 4050 years: $9.4 \%$, 50-60 years: $9.1 \%$, $\geq 60$ years: $10.7 \%)(p<$ 0.001). Furthermore, we divided each age group into three glycemic stages (NGT, prediabetes, DM) to adjust the effect of age on glycemic status (Fig. 3). When participants were in NGT or prediabetes, younger individuals had a higher proportion of multiphasic curves. However, when the glycemic status progressed to diabetes, quite a low percentage of individuals in all age groups had multiphasic curves.

\section{Types of glucose curve shape as the indicator for insulin resistance and $\beta$-cell function}

Surrogate markers of insulin sensitivity and $\beta$-cell function including HOMA-IR, Matsuda Index, insulinogenic index, and disposition index were significantly different between the monophasic and multiphasic groups (Table 1). After stratification in glycemic status, the difference in insulinogenic index remained significant at every status of glycemic metabolism. However, the other three indexes no longer showed significant differences in individuals with DM. In addition, no significant differences between the two groups were noted for HOMA-IR in participants with prediabetes (Table 2).

\section{OGTT glucose peak time, nadir time, and insulin peak} time in relation to insulin resistant and $\beta$-cell function The multiphasic group could be further divided into two categories by the time when glucose is lowest. The triphasic curve all reached the nadir at $1 \mathrm{~h}$, while the biphasic curve's nadir time could be $1 \mathrm{~h}$ or $2 \mathrm{~h}$. Regarding $\beta$-cell function, the curve with a nadir time of $2 \mathrm{~h}$ had significantly lower insulinogenic index and disposition 
Table 1 Demographic and metabolic characteristics of 9059 participants with monophasic versus multiphasic OGTT glucose response curve and 1150 participants with biphasic versus triphasic

\begin{tabular}{|c|c|c|c|c|c|c|}
\hline Variables & $\begin{array}{l}\text { Monophasic group } \\
(n=7909)\end{array}$ & $\begin{array}{l}\text { Multiphasic group } \\
(n=1150)\end{array}$ & $P$ value & $\begin{array}{l}\text { Biphasic group } \\
(n=548)\end{array}$ & $\begin{array}{l}\text { Triphasic group } \\
(n=602)\end{array}$ & $P$ value \\
\hline Age (years) & $38.6 \pm 13.6$ & $35.4 \pm 13.5$ & $<0.001$ & $35.1 \pm 13.7$ & $35.8 \pm 13.2$ & 0.391 \\
\hline Sex (male/female), n\% & $\begin{array}{l}2100(26.6) / \\
5809(73.4)\end{array}$ & $\begin{array}{l}219(19.0) / \\
931(81.0)\end{array}$ & $<0.001$ & $\begin{array}{l}106(19.3) / \\
442(80.7)\end{array}$ & $\begin{array}{l}113(18.8) / \\
489(81.2)\end{array}$ & 0.805 \\
\hline FBG (mmol/L) & $5.6 \pm 13.5$ & $5.2 \pm 0.6$ & $<0.001$ & $5.2 \pm 0.6$ & $5.2 \pm 0.6$ & 0.189 \\
\hline $30 \mathrm{~min}$ GLU (mmol/L) & $9.5 \pm 2.0$ & $8.3 \pm 1.6$ & $<0.001$ & $8.4 \pm 1.6$ & $8.2 \pm 1.6$ & $<0.001$ \\
\hline 2 h GLU (mmol/L) & $8.2 \pm 3.2$ & $6.3 \pm 2.0$ & $<0.001$ & $5.4 \pm 1.8$ & $7.2 \pm 1.9$ & $<0.001$ \\
\hline FINS & $14.8 \pm 8.7$ & $13.5 \pm 7.9$ & $<0.001$ & $13.2 \pm 8.4$ & $13.7 \pm 7.5$ & 0.328 \\
\hline $30 \mathrm{~min}$ INS & $97.7 \pm 59.6$ & $123.5 \pm 67.1$ & $<0.001$ & $105.6 \pm 62.0$ & $139.7 \pm 67.5$ & $<0.001$ \\
\hline $2 \mathrm{~h} \mathrm{INS}$ & $106.9 \pm 66.9$ & $76.8 \pm 57.8$ & $<0.001$ & $54.7 \pm 43.2$ & $96.8 \pm 62.0$ & $<0.001$ \\
\hline \multicolumn{7}{|l|}{ Glycemic status(\%) } \\
\hline NGT & $4253(53.8)$ & $903(78.5)$ & & $486(88.7)$ & $417(69.3)$ & \\
\hline IFG/IGT/IFG + IGT & $2362(29.9)$ & $206(17.9)$ & $<0.001$ & $50(9.1)$ & $156(25.9)$ & $<0.001$ \\
\hline DM & $1294(16.3)$ & $41(3.6)$ & & $12(2.2)$ & $29(4.8)$ & \\
\hline Glucose AUC $\left(\mathrm{mg} \cdot \mathrm{dL}^{-1} \cdot \mathrm{h}^{-1}\right)$ & $1473.5 \pm 437.1$ & $1181.2 \pm 257.8$ & $<0.001$ & $1180.0 \pm 259.7$ & $1182.4 \pm 256.2$ & 0.876 \\
\hline Insulin AUC (mg.dL $\left.{ }^{-1} \cdot \mathrm{h}^{-1}\right)$ & $16,299.7 \pm 8297.5$ & $13,968.7 \pm 7498.6$ & $<0.001$ & $13,182.2 \pm 7277.7$ & $14,684.7 \pm 7629.9$ & 0.001 \\
\hline HOMA-IR & $3.8 \pm 2.6$ & $3.1 \pm 2.0$ & $<0.001$ & $3.1 \pm 2.1$ & $3.2 \pm 1.8$ & 0.595 \\
\hline Matsuda Index & $2.9 \pm 1.9$ & $3.8 \pm 2.5$ & $<0.001$ & $4.0 \pm 2.7$ & $3.6 \pm 2.3$ & 0.018 \\
\hline Insulinogenic index & $25.1 \pm 23.0$ & $42.9 \pm 37.7$ & $<0.001$ & $36.0 \pm 35.9$ & $49.1 \pm 38.2$ & $<0.001$ \\
\hline Disposition index & $12.7 \pm 14.1$ & $16.6 \pm 17.8$ & $<0.001$ & $13.7 \pm 15.4$ & $19.2 \pm 19.4$ & $<0.001$ \\
\hline
\end{tabular}

Values are reported as the mean \pm SD or $\mathrm{n}(\%)$. FBG fasting blood glucose, $30 \mathrm{~min}$ GLU glucose at $30 \mathrm{~min}, 2 \mathrm{~h}$ GLU glucose at $120 \mathrm{~min}$, FINS fasting insulin, $30 \mathrm{~min}$ INS insulin at $30 \mathrm{~min}, 2 \mathrm{~h}$ INS insulin at $1200 \mathrm{~min}$, NGT normal glucose tolerance, IFG impaired fasting glucose, IGT impaired glucose tolerance, DM diabetes mellitus, AUC area under the curve

index (Table 3). But there was no marked difference between the two groups for the HOMA-IR and Matsuda Index. Early glucose and insulin peak times were all associated with lower HOMA-IR $(p<0.001)$ and a higher disposition index $(p<0.001)$ (Tables 4 and 5$)$.

\section{Change in the OGTT glucose curve shape and risk of impaired glucose metabolism}

There were 635 participants who underwent OGTT twice. Table 5 shows baseline physical and metabolic characteristics of all the participants with a stable glucose response curve shape compared to those with unstable shape. Of the participants, $80.3 \%$ exhibited no change in shape between the baseline and the second OGTT (Table 6). Individuals who maintained a monophasic glucose response curve had the lowest rate of NGT, and those who maintained a multiphasic glucose response curve had the highest rate of NGT at baseline. Individuals with a stable monophasic glucose response shape had significantly higher fasting and 2hPG. Persistence of the monophasic shape was, in general, associated with worse insulin sensitivity and reduced $\beta$-cell function. Individuals whose glucose response curve changed from multiphasic to monophasic tended to have a higher rate of deterioration in glucose metabolism (Table 7).

\section{Discussion}

The present investigation revealed the following findings regarding the shape of OGTT curve in a large Chinese population: 1) multiphasic OGTT response curves were not rare in Chinese people, accounting for more than $10 \%$ of the population; 2) monophasic curves were more common in older people and in those with worse glycemic status; 3 ) individuals with monophasic curves had poorer $\beta$-cell function than individuals with multiphasic curves, despite having similar glycemic status; 4) individuals who were in NGT with a monophasic shape showed significantly worse insulin sensitivity, as reflected by the HOMA-IR and Matsuda Index, compared to patients with a multiphasic curve; 5) $\beta$-cell function was better in patients whose glucose concentration started to decrease at $60 \mathrm{~min}$ compared to later among the multiphasic curve group; and 6) the number of phases of the same subject could change at different times, and the number of phases increased with the improvement of glucose status.

In studies of nondiabetic individuals, the morphology of the monophasic glucose response curve is the dominant phenotype, up to $57-84 \%$ in adults $[12,13,17,22$, 23 and $35-69 \%$ in obese youth at high risk for T2D [6, $7,9,10,24]$. Our study showed that about $88.3 \%$ of 

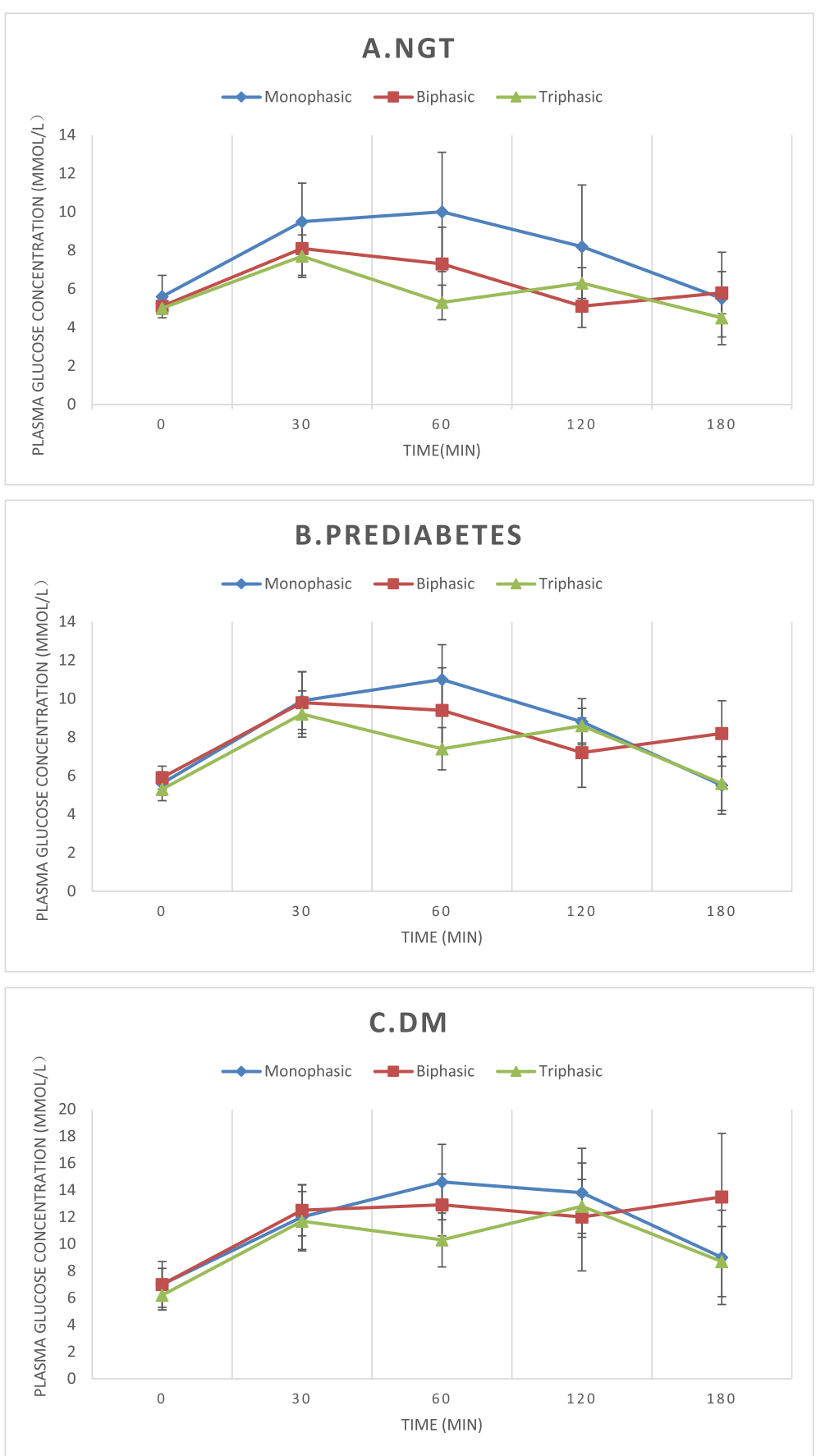

Fig. 2 Glucose during a 3-h OGTT in monophasic, biphasic and triphasic groups among different glycemic status. NGT: normal glucose tolerance, DM: diabetes mellitus

individuals had monophasic response curves and $11.7 \%$ had multiphasic response curves. Combining our present research with previous studies in youth $[6,10]$ and adults [12], the multiphasic group tends to be associated with younger age compared with the monophasic group. Our study further found that there was little difference between the two glucose curve shape groups when the glycemic status reached diabetes, and both young and old individuals had an extremely low proportion of multiphasic OGTT response curve.

Cross-sectional studies in youths [6-13] and adults $[11-13,23]$ showed that the shape of the OGTT glucose response curve could indicate insulin sensitivity and $\beta$ cell function, as well as differentiate type 2 diabetes risk. 


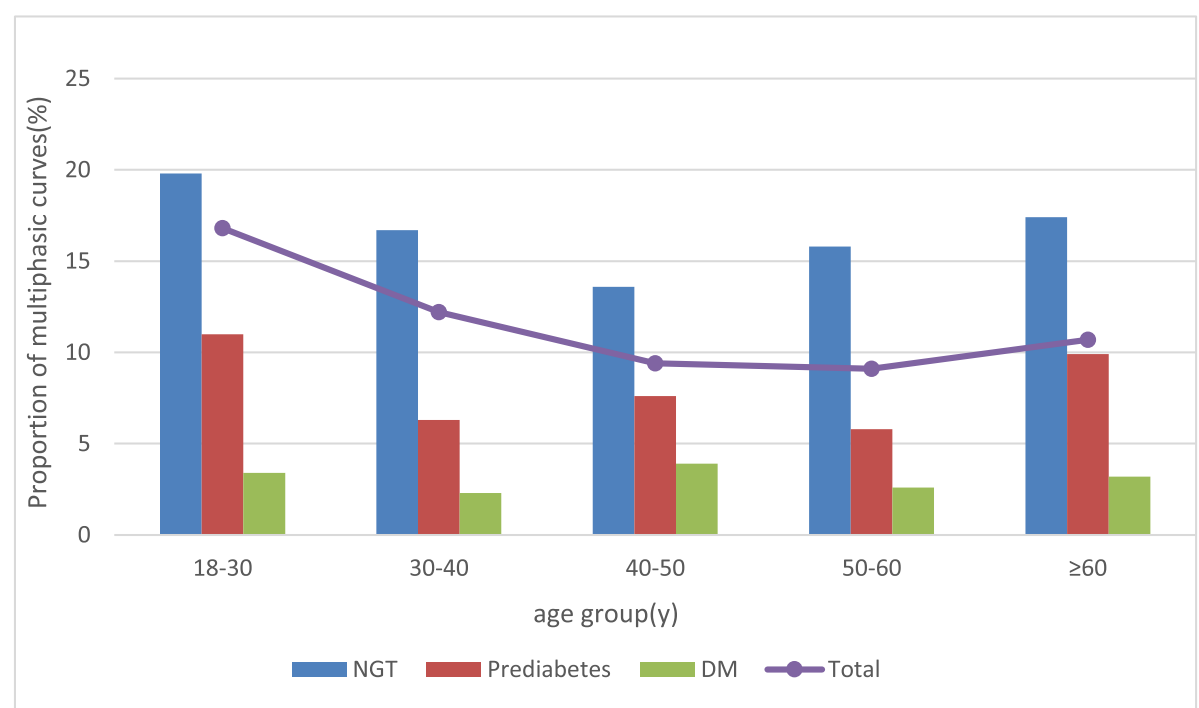

Fig. 3 Proportion of multiphasic curves at different age group and glycemic status NGT: normal glucose tolerance, DM: diabetes mellitus

Table 2 Demographic and metabolic characteristics of 9059 participants with monophasic versus multiphasic OGTT-glucose response curve in different glycemic status

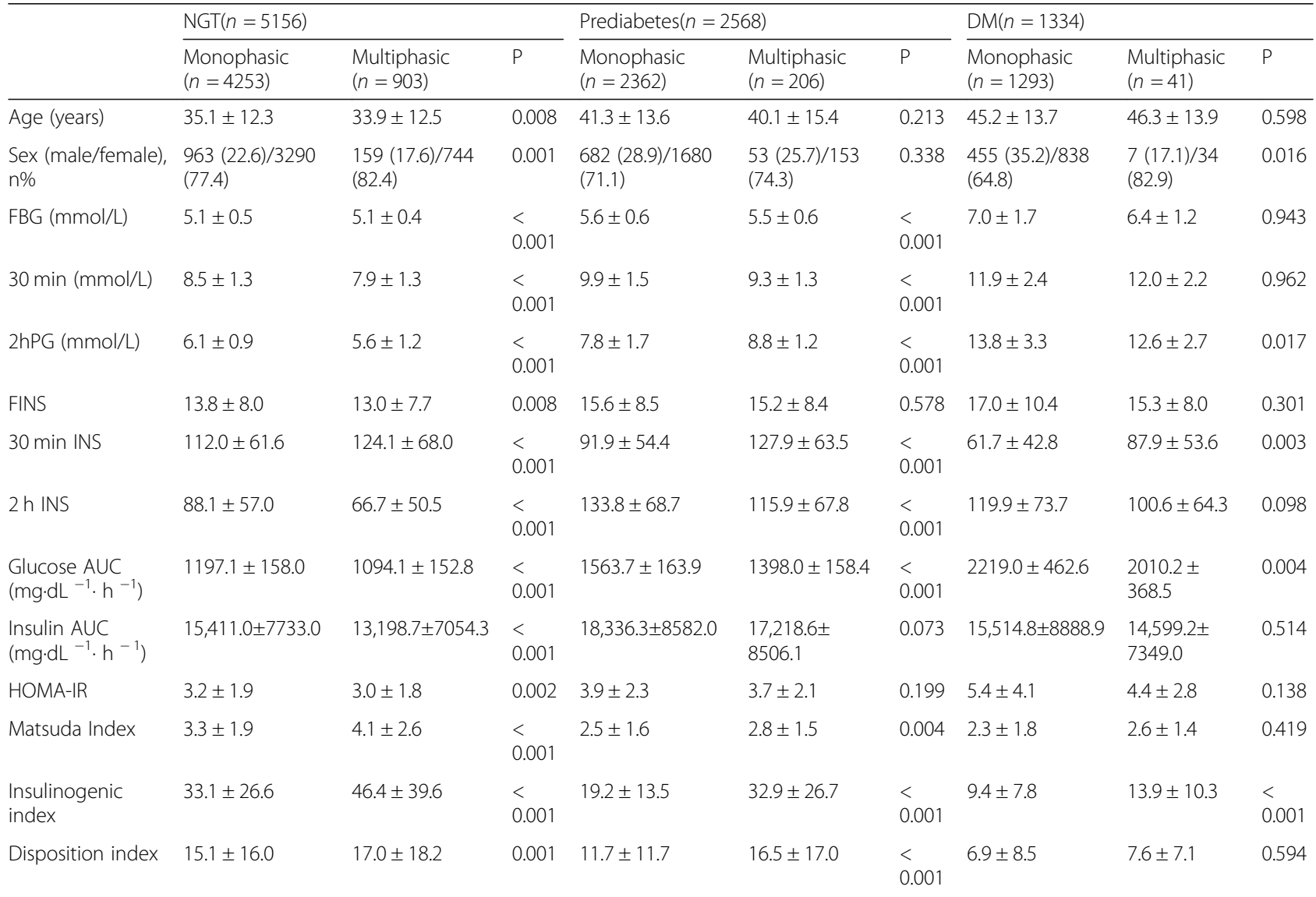


Table 3 Demographic and metabolic characteristics of 1150 participants with OGTT glucose nadir at 60 min versus at 120 min

\begin{tabular}{|c|c|c|c|}
\hline & $\begin{array}{l}\text { OGTT glucose nadir at } 60 \mathrm{~min} \\
(n=688)\end{array}$ & $\begin{array}{l}\text { OGTT glucose nadir at } 120 \mathrm{~min} \\
(n=462)\end{array}$ & $P$ \\
\hline Age (years) & $35.5 \pm 13.2$ & $35.3 \pm 13.8$ & 0.824 \\
\hline Sex (male/female), n\% & $119(17.3) / 569(82.7)$ & $100(21.6) / 362(78.4)$ & 0.066 \\
\hline FBG (mmol/L) & $5.2 \pm 0.6$ & $5.2 \pm 0.6$ & 0.069 \\
\hline 30 min GLU(mmol/L) & $8.2 \pm 1.6$ & $8.5 \pm 1.6$ & 0.004 \\
\hline $2 \mathrm{~h} \mathrm{GLU}(\mathrm{mmol} / \mathrm{L})$ & $7.1 \pm 2.0$ & $5.2 \pm 1.6$ & $<0.001$ \\
\hline FINS & $13.5 \pm 7.4$ & $13.4 \pm 8.6$ & 0.743 \\
\hline $30 \mathrm{~min}$ INS & $137.7 \pm 67.5$ & $102.3 \pm 60.6$ & $<0.001$ \\
\hline $2 \mathrm{~h} \mathrm{INS}$ & $92.6 \pm 61.3$ & $53.2 \pm 42.3$ & $<0.001$ \\
\hline \multicolumn{4}{|l|}{ Glycemic status(\%) } \\
\hline NGT(\%) & $489(71.1)$ & $414(89.6)$ & \\
\hline IFG/IGT/IFG + IGT(\%) & $167(24.3)$ & $39(8.4)$ & $<0.001$ \\
\hline $\mathrm{DM}(\%)$ & $32(4.7)$ & $9(1.9)$ & \\
\hline Glucose AUC (mg.dL $\left.{ }^{-1} \cdot \mathrm{h}^{-1}\right)$ & $1175.3 \pm 267.0$ & $1190.0 \pm 243.4$ & 0.342 \\
\hline Insulin $A \cup C\left(m g \cdot d L^{-1} \cdot h^{-1}\right)$ & $14,349.1 \pm 7572.7$ & $13,402.2 \pm 7358.6$ & 0.036 \\
\hline HOMAIR & $3.1 \pm 1.8$ & $3.1 \pm 2.2$ & 0.957 \\
\hline Matsuda Index & $3.8 \pm 2.5$ & $3.8 \pm 2.4$ & 0.670 \\
\hline Insulinogenic index & $49.7 \pm 40.8$ & $32.7 \pm 29.7$ & $<0.001$ \\
\hline Disposition index & $18.8 \pm 19.0$ & $13.1 \pm 15.3$ & $<0.001$ \\
\hline
\end{tabular}

Values are reported as the mean \pm SD or $\mathrm{n}(\%)$. FBG fasting blood glucose, $30 \mathrm{~min}$ GLU glucose at $30 \mathrm{~min}, 2 \mathrm{~h}$ GLU glucose at $120 \mathrm{~min}$, FINS fasting insulin, 30 min INS insulin at $30 \mathrm{~min}, 2 \mathrm{~h}$ INS insulin at $1200 \mathrm{~min}, N G T$ normal glucose tolerance, IFG impaired fasting glucose, IGT impaired glucose tolerance, DM diabetes mellitus, AUC area under the curve

Table 4 Demographic and metabolic characteristics of 9059 participants with OGTT glucose peak at 30 min, 60 min versus 120 min

\begin{tabular}{|c|c|c|c|c|}
\hline & $\begin{array}{l}\text { OGTT glucose peak at } 30 \mathrm{~min} \\
(n=4599)\end{array}$ & $\begin{array}{l}\text { OGTT glucose peak at } 60 \mathrm{~min} \\
(n=3912)\end{array}$ & $\begin{array}{l}\text { OGTT glucose peak at } 120 \mathrm{~min} \\
(n=548)\end{array}$ & $P$ \\
\hline Age (years) & $35.8 \pm 12.8$ & $40.1 \pm 13.6$ & $44.9 \pm 14.9$ & $<0.001$ \\
\hline Sex (male/female), n\% & $974(21.2) / 3625(78.8)$ & $1178(30.1) / 2734(69.9)$ & $167(30.5) / 381(69.5)$ & $<0.001$ \\
\hline $\mathrm{FBG}(\mathrm{mmol} / \mathrm{L})$ & $5.2 \pm 0.6$ & $5.7 \pm 1.1$ & $6.6 \pm 2.0$ & $<0.001$ \\
\hline $30 \mathrm{~min} \mathrm{GLU}(\mathrm{mmol} / \mathrm{L})$ & $8.8 \pm 1.6$ & $9.8 \pm 2.1$ & $10.6 \pm 3.0$ & $<0.001$ \\
\hline $2 \mathrm{~h} \mathrm{GLU}(\mathrm{mmol} / \mathrm{L})$ & $6.3 \pm 1.5$ & $8.9 \pm 2.8$ & $14.4 \pm 4.3$ & $<0.001$ \\
\hline FINS & $13.6 \pm 7.7$ & $15.6 \pm 9.2$ & $16.5 \pm 10.3$ & $<0.001$ \\
\hline $30 \mathrm{~min}$ INS & $121.8 \pm 63.6$ & $82.0 \pm 50.1$ & $62.6 \pm 48.3$ & $<0.001$ \\
\hline $2 \mathrm{~h}$ INS & $85.9 \pm 58.8$ & $121.5 \pm 68.9$ & $116.0 \pm 73.2$ & $<0.001$ \\
\hline \multicolumn{5}{|l|}{ Glycemic status(\%) } \\
\hline NGT(\%) & 3749 (81.5) & $1386(35.4)$ & $21(3.8)$ & \\
\hline IFG/IGT/IFG + IGT(\%) & $766(16.7)$ & $1693(43.3)$ & 109 (19.9) & \multirow[t]{2}{*}{$<0.001$} \\
\hline $\mathrm{DM}(\%)$ & $84(1.8)$ & $833(21.3)$ & $418(76.3)$ & \\
\hline Glucose AUC (mg.dL $\left.{ }^{-1} \cdot \mathrm{h}^{-1}\right)$ & $1202.6 \pm 212.3$ & $1609.3 \pm 385.4$ & $2163.9 \pm 643.5$ & $<0.001$ \\
\hline Insulin $\mathrm{AUC}\left(\mathrm{mg} \cdot \mathrm{dL}^{-1} \cdot \mathrm{h}^{-1}\right)$ & $15,048.7 \pm 7705.2$ & $17,313.6 \pm 8561.2$ & $14,668.6 \pm 8865.8$ & $<0.001$ \\
\hline HOMAIR & $3.2 \pm 1.9$ & $4.1 \pm 2.8$ & $4.9 \pm 3.9$ & $<0.001$ \\
\hline Matsuda Index & $3.4 \pm 2.1$ & $2.6 \pm 1.7$ & $2.8 \pm 2.1$ & $<0.001$ \\
\hline Insulinogenic index & $36.1 \pm 30.0$ & $18.8 \pm 16.2$ & $15.0 \pm 20.9$ & $<0.001$ \\
\hline Disposition index & $15.6 \pm 16.2$ & $11.0 \pm 12.4$ & $8.6 \pm 12.6$ & $<0.001$ \\
\hline
\end{tabular}

Values are reported as the mean \pm SD or $\mathrm{n}(\%)$. FBG fasting blood glucose, 30 min GLU glucose at 30 min, 2 h GLU glucose at 120 min, FINS fasting insulin, 30 min INS insulin at $30 \mathrm{~min}, 2 \mathrm{~h}$ INS insulin at $1200 \mathrm{~min}$, NGT normal glucose tolerance, IFG impaired fasting glucose, IGT impaired glucose tolerance, DM diabetes mellitus, AUC area under the curve 
Table 5 Demographic and metabolic characteristics of 9059 participants with OGTT insulin peak at 30 min, 60 min versus 120 min

\begin{tabular}{|c|c|c|c|c|c|}
\hline & $\begin{array}{l}\text { OGTT insulin peak at } 30 \\
\min _{(n=2935)}\end{array}$ & $\begin{array}{l}\text { OGTT insulin peak at } 60 \\
\min \\
(n=3729)\end{array}$ & $\begin{array}{l}\text { OGTT insulin peak at } 120 \\
\min \\
(n=2279)\end{array}$ & $\begin{array}{l}\text { OGTT insulin peak at } 180 \\
\min \\
(n=116)\end{array}$ & $P$ \\
\hline Age (years) & $36.1 \pm 13.5$ & $37.9 \pm 13.1$ & $41.3 \pm 13.9$ & $39.7 \pm 14.4$ & $<0.001$ \\
\hline Sex (male/female), n\% & $610(20.8) / 2325(79.2)$ & $1073(28.8) / 2656(71.2)$ & $611(26.8) / 1668(73.2)$ & $25(21.2) / 91(78.8)$ & $<0.001$ \\
\hline $\mathrm{FBG}(\mathrm{mmol} / \mathrm{L})$ & $5.2 \pm 1.0$ & $5.5 \pm 1.0$ & $5.9 \pm 1.2$ & $6.3 \pm 1.6$ & $<0.001$ \\
\hline $30 \mathrm{~min} \mathrm{GLU}(\mathrm{mmol} / \mathrm{L})$ & $8.6 \pm 1.7$ & $9.4 \pm 2.0$ & $10.1 \pm 2.0$ & $10.2 \pm 2.6$ & $<0.001$ \\
\hline $2 \mathrm{~h} \mathrm{GLU}(\mathrm{mmol} / \mathrm{L})$ & $6.9 \pm 2.4$ & $7.1 \pm 2.6$ & $10.3 \pm 3.3$ & $12.9 \pm 4.2$ & $<0.001$ \\
\hline FINS & $13.7 \pm 7.9$ & $14.8 \pm 8.8$ & $15.5 \pm 8.8$ & $17.2 \pm 11.2$ & $<0.001$ \\
\hline $30 \mathrm{~min}$ INS & $133.0 \pm 66.1$ & $95.4 \pm 54.9$ & $71.3 \pm 43.7$ & $56.4 \pm 35.1$ & $<0.001$ \\
\hline $2 \mathrm{~h}$ INS & $85.5 \pm 59.7$ & $89.6 \pm 56.4$ & $147.2 \pm 70.6$ & $117.0 \pm 62.9$ & $<0.001$ \\
\hline \multicolumn{6}{|l|}{ Glycemic status(\%) } \\
\hline NGT(\%) & $2211(75.3)$ & $2514(67.4)$ & $424(18.6)$ & $7(5.3)$ & \\
\hline IFG/IGT/IFG + IGT(\%) & $549(18.7)$ & $893(24.0)$ & $1089(47.8)$ & $38(32.7)$ & $\begin{array}{l}< \\
0.001\end{array}$ \\
\hline DM(\%) & $175(6.0)$ & $322(8.6)$ & 766 (33.6) & $71(61.9)$ & \\
\hline${ }_{-1}^{\text {Glucose }}$ AUC $\left(\mathrm{mg}^{-1} \cdot \mathrm{LL}^{-1} \cdot \mathrm{h}\right.$ & $1239.8 \pm 329.6$ & $1389.2 \pm 362.0$ & $1738.5 \pm 440.9$ & $2070.4 \pm 580.7$ & $<0.001$ \\
\hline${ }_{1}^{\text {Insulin }} \mathrm{AUC}\left(\mathrm{mg} \cdot \mathrm{dL}^{-1} \cdot \mathrm{h}^{-}\right.$ & $14,403.2 \pm 7536.1$ & $16,046.0 \pm 8141.5$ & $17,980.4 \pm 8741.5$ & $17,006.3 \pm 8977.3$ & $<0.001$ \\
\hline HOMAIR & $3.3 \pm 2.1$ & $3.7 \pm 2.6$ & $4.2 \pm 2.8$ & $5.1 \pm 4.5$ & $<0.001$ \\
\hline Matsuda Index & $3.5 \pm 2.2$ & $2.9 \pm 1.9$ & $2.6 \pm 1.8$ & $2.8 \pm 2.6$ & $<0.001$ \\
\hline Insulinogenic index & $41.8 \pm 33.4$ & $23.9 \pm 19.4$ & $15.1 \pm 13.5$ & $11.7 \pm 10.2$ & $<0.001$ \\
\hline Disposition index & $17.4 \pm 17.6$ & $12.7 \pm 13.5$ & $9.0 \pm 10.7$ & $6.7 \pm 7.1$ & $<0.001$ \\
\hline
\end{tabular}

Values are reported as the mean \pm SD or $\mathrm{n}(\%)$. FBG fasting blood glucose, 30 min GLU glucose at 30 min, $2 \mathrm{~h}$ GLU glucose at 120 min, FINS fasting insulin, 30 min INS insulin at $30 \mathrm{~min}, 2 \mathrm{~h}$ INS insulin at $1200 \mathrm{~min}$, NGT normal glucose tolerance, IFG impaired fasting glucose, IGT impaired glucose tolerance, DM diabetes mellitus, AUC area under the curve

Obese youths with monophasic glucose response curves were worse in both hepatic and peripheral insulin sensitivity measured by the clamp method compared with the biphasic group, as well as in $\beta$-cell function, which was indicated by impaired disposition index as a result of lacking in a compensatory increase in first and secondphase insulin secretion [6]. Evidence from patients with suspected gestational diabetes who underwent $3 \mathrm{~h}$ OGTT showed that a greater number of phases in the OGTT glucose response curve was associated with a healthier metabolic state, which suggests that a biphasic response curve may be associated with a lower incidence of prediabetes and T2D [13]. In our study, $\beta$-cell function was better in individuals with multiphasic glucose response curve. As for insulin sensitivity, the difference was still significant in the NGT group, but the difference did not remain significant in the diabetes group. The most likely reason is that defects in $\beta$-cell function are more severe in Chinese patients with diabetes than those in Europeans or Americans, resulting in more serious deficiencies in insulin secretion [25].

Am American study conducted in adult patients showed that the baseline and subsequent glucose concentrations in the OGTT could stratify the risk for progression to T2D; that is, a faster return to the FPG concentration may suggest a lower risk of T2D [22]. Our study further found that individuals with multiphasic curves whose plasma glucose concentration reached the lowest point at $60 \mathrm{~min}$ had better $\beta$-cell function than those with a nadir at $120 \mathrm{~min}$. Consistent with previous studies [26], we found that the earlier the glucose/insulin peak in the OGTT curve, the better the $\beta$-cell function.

Our data showed that individuals whose response glucose curve changed from multiphasic to monophasic during follow-up were more prone to deteriorate in glycemic status than those whose glucose response curves changed from monophasic curves to multiphasic curves. This result is supported by several longitudinal studies. A 7-8 year longitudinal study demonstrated that prediabetic patients with monophasic curves had twice the incidence of diabetes as those with biphasic curves, despite similar fasting and 2hPG concentrations [22]. Individuals with a monophasic curve at baseline and those whose patterns changed from biphasic to monophasic had an increased risk for impaired glucose metabolism [14]. We also found that individuals with a persistent monophasic curve had worse insulin sensitivity and $\beta$ cell function than those with other forms at baseline. 
Table 6 Demographic and metabolic characteristics of 502 participants with stable versus unstable OGT-glucose response curve

\begin{tabular}{|c|c|c|c|c|c|}
\hline & \multicolumn{2}{|l|}{ Stable } & \multicolumn{2}{|l|}{ Unstable } & \multirow[t]{2}{*}{$P$ value } \\
\hline & Monophasic & Multiphasic & Monophasic to Multiphasic & Multiphasic to Monophasic & \\
\hline N & 371 & 9 & 55 & 67 & \\
\hline Age (years) & $35.5 \pm 12.3$ & $37.0 \pm 11.3$ & $32.9 \pm 13.2$ & $35.1 \pm 14.6$ & 0.535 \\
\hline Sex (male/female, \%) & $62(16.7) / 309$ (83.3) & $2(22.2) / 7(77.8)$ & $9(16.4) / 46(83.6)$ & $9(13.4) / 58(86.6)$ & 0.878 \\
\hline $\mathrm{FBG}(\mathrm{mmol} / \mathrm{L})$ & $5.6 \pm 0.9$ & $5.1 \pm 0.6$ & $5.2 \pm 0.6$ & $5.2 \pm 0.5$ & $<0.001$ \\
\hline 30 min GLU(mmol/L) & $9.2 \pm 1.7$ & $8.2 \pm 1.4$ & $8.5 \pm 1.3$ & $8.3 \pm 1.4$ & $<0.001$ \\
\hline $2 \mathrm{~h} \mathrm{GLU}(\mathrm{mmol} / \mathrm{L})$ & $8.1 \pm 2.7$ & $5.6 \pm 1.2$ & $6.5 \pm 1.6$ & $6.5 \pm 1.7$ & $<0.001$ \\
\hline FINS & $17.7 \pm 9.2$ & $11.1 \pm 5.3$ & $15.4 \pm 10.0$ & $16.8 \pm 9.7$ & 0.075 \\
\hline 30 min INS & $111.2 \pm 65.3$ & $152.8 \pm 69.7$ & $131.2 \pm 74.8$ & $150.2 \pm 67.7$ & $<0.001$ \\
\hline $2 \mathrm{~h}$ INS & $128.8 \pm 72.2$ & $69.3 \pm 46.7$ & $101.7 \pm 66.9$ & $97.0 \pm 65.7$ & $<0.001$ \\
\hline \multicolumn{6}{|l|}{ Glycemic status(n,\%) } \\
\hline NGT & $181(48.8)$ & $9(100)$ & $42(76.4)$ & $51(76.1)$ & \\
\hline IFG/IGT/IFG + IGT & $145(39.1)$ & 0 & $12(21.8)$ & $16(23.9)$ & $<0.001$ \\
\hline DM & $45(12.1)$ & 0 & $1(1.8)$ & 0 & \\
\hline $\begin{array}{l}\text { Glucose AUC } \\
\left(\mathrm{mg} \cdot \mathrm{dL}^{-1} \cdot \mathrm{h}^{-1}\right)\end{array}$ & $1461.3 \pm 366.0$ & $1100.2 \pm 83.1$ & $1230.5 \pm 231.0$ & $1184.8 \pm 208.6$ & $<0.001$ \\
\hline $\begin{array}{l}\text { Insulin AUC } \\
\left(\mathrm{mg} \cdot \mathrm{dL}^{-1} \cdot \mathrm{h}^{-1}\right)\end{array}$ & $19,184.5 \pm 8734.1$ & $13,817.2 \pm 5128.2$ & $17,677.0 \pm 90,944.7$ & $18,637.6 \pm 8730.2$ & 0.068 \\
\hline HOMA-IR & $4.4 \pm 2.6$ & $2.6 \pm 1.2$ & $3.6 \pm 2.4$ & $3.9 \pm 2.3$ & 0.012 \\
\hline Matsuda Index & $2.4 \pm 1.6$ & $3.8 \pm 2.3$ & $3.1 \pm 2.0$ & $3.1 \pm 2.0$ & $<0.001$ \\
\hline Insulinogenic index & $29.6 \pm 28.3$ & $52.8 \pm 34.1$ & $37.7 \pm 23.7$ & $55.2 \pm 56.7$ & $<0.001$ \\
\hline Disposition index & $17.2 \pm 17.3$ & $16.3 \pm 7.0$ & $19.2 \pm 18.2$ & $24.3 \pm 20.4$ & 0.025 \\
\hline
\end{tabular}

Values are reported as the mean \pm SD or $\mathrm{n}(\%)$. FBG fasting blood glucose, $30 \mathrm{~min}$ GLU glucose at $30 \mathrm{~min}, 2 \mathrm{~h}$ GLU glucose at $120 \mathrm{~min}, \mathrm{FINS}$ fasting insulin, $30 \mathrm{~min}$ INS insulin at $30 \mathrm{~min}, 2 \mathrm{~h}$ INS insulin at $1200 \mathrm{~min}$, NGT normal glucose tolerance, IFG impaired fasting glucose, IGT impaired glucose tolerance, DM diabetes mellitus, AUC area under the curve

The strengths of the present investigation include the following: 1 ) it is the first large-scale (up to 10,000) investigation of the relationship between the OGTT glucose response curve and insulin resistance/ $\beta$-cell function in Chinese people; 2) the study included people with different glucose metabolic states and across different age groups. Potential perceived limitations would be that we have no anthropometric data, such as body mass index (BMI) and waist circumference, which could have an influence on glycemic status. But previous research showed that the OGTT response curve shape remained

Table 7 The relationship between the change of the phase number and the change of the glycemic status

\begin{tabular}{llllll}
\hline $\begin{array}{l}\text { Glycemic } \\
\text { status }\end{array}$ & & Improve & Unchanging & Aggravation & Total \\
\hline $\begin{array}{l}\text { Change of } \\
\text { the phase- } \\
\text { number }\end{array}$ & Decrease & 7 & $49(73.1 \%)$ & $11(16.4 \%)$ & 67 \\
& Unchanging & $\begin{array}{l}65.4 \%) \\
(17.1 \%)\end{array}$ & $245(64.5 \%)$ & $70(18.4 \%)$ & 380 \\
& $\begin{array}{lllll}11 \\
\text { Increase }\end{array}$ & $38(69.1 \%)$ & $6(10.9 \%)$ & 55 \\
& & $(20.0 \%)$ & & & \\
Total & 83 & 332 & 87 & 502 \\
\hline
\end{tabular}

Values are reported as $\mathrm{N}(\mathrm{n} \%)$ strongly associated with insulin sensitivity and $\beta$-cell function after adjusting for BMI, blood pressure, and waist circumference $[6,8]$. In addition, our research follows the standard methods used in China. The OGTT glucose response curve shape was determined by data only at $0,30,60,120$, and $180 \mathrm{~min}$, lacking $90 \mathrm{~min}$ glucose data, which may have led to an underestimation in the phase of the curve. Investigations of the change in patterns or shapes of the OGTT glucose response curves did not have regular follow-up.

\section{Conclusions}

In summary, the present study is the first to demonstrate that in a large Chinese population, the monophasic OGTT glucose response curve was associated with reduced $\beta$-cell function, higher HOMA-IR, and older age. However, prospective longitudinal studies are needed to verify the usefulness of the OGTT glucose response curve in predicting progression to prediabetes or T2D in Chinese. Further, it remains essential to examine whether any factors could shift the OGTT glucose response curve from monophasic to multiphasic. 


\section{Abbreviations}

2hPG: 2-h plasma glucose; BMl: Body mass index; DM: Diabetes mellitus; FINS: Fasting serum insulin; FPG: Fasting plasma glucose; IFG: Impaired fasting glucose; IGT: Impaired glucose tolerance; NGT: Normal glucose tolerance; OGTT: Oral glucose tolerance test; T2D: Type 2 diabetes

\section{Acknowledgments}

The authors are grateful to the Staff of the Peking Union Medical College Hospital and all who actively participated in the study.

\section{Authors' contributions}

XQC and HBZ had full access to all of the data in the study and take responsibility for the integrity of the data and the accuracy of the data analysis. Study concept and design: XQC, NY, HBZ, and YXL. Acquisition of data: XQC and LQ. Analysis and interpretation of data: XQC, NY, and HBZ. Drafting of the manuscript: NY, XQC, and HBZ. Critical revision of the manuscript for important intellectual content: XQC, NY, LQ, LLX, FP, WL, QS, HBZ, and YXL. Statistical analysis: XQC, NY, and HBZ. Obtained funding: HBZ Administrative, technical, and material support: XQC, NY, and HBZ. Study supervision: XQC, HBZ, and YXL. All authors have approved the final article.

\section{Funding}

The work was supported in part by the National Natural Science Foundation of China (91846106, 71432004), Non-profit Central Research Institute Fund of Chinese Academy of Medical Sciences (2017PT32020, 2018PT32001), Chinese Academy of Medical Sciences Innovation Fund for Medical Sciences (CIFMS2016-I2M-4-001), Training Program for Excellent Talents in Dongcheng District, and the Education Reforming Program, Peking Union Medical College (No. 2018zlgc0119). These organizations had no role in the design and conduct of the study; collection, management, analysis, and interpretation of the data; preparation, review, or approval of the manuscript; or the decision to submit the manuscript for publication.

\section{Availability of data and materials}

The datasets used and analyzed during the current study are available from the corresponding author on reasonable request.

\section{Ethics approval and consent to participate}

The study was conducted in accordance with the ethical rules of the Helsinki Declaration. The study protocol was approved by the Ethics Committee of Peking Union Medical College Hospital. The permission to access the raw data was granted by the Ethics Committee of Peking Union Medical College Hospital.

\section{Consent for publication}

Not applicable.

\section{Competing interests}

The authors declare that they have no competing interests.

\section{Author details}

Department of Clinical Laboratory, Peking Union Medical College Hospital, Chinese Academy of Medical Sciences \& Peking Union Medical College, Beijing, China. ${ }^{2}$ Department of Endocrinology, Key Laboratory of Endocrinology, Ministry of Health, Peking Union Medical College Hospital Chinese Academy of Medical Sciences \& Peking Union Medical College, Beijing, China.

Received: 29 June 2019 Accepted: 18 October 2019 Published online: 05 November 2019

\section{References}

1. Rehman K, Akash MS. Mechanisms of inflammatory responses and development of insulin resistance: how are they interlinked? J Biomed Sci. 2016:23:87.

2. Rehman $\mathrm{K}, \mathrm{Akash}$ MSH. Mechanism of generation of oxidative stress and pathophysiology of type 2 diabetes mellitus: how are they interlinked? J Cell Biochem. 2017;118:3577-85.

3. Schwartz SS, Epstein S, Corkey BE, Grant SF, Gavin JR 3rd, Aguilar RB. The time is right for a new classification system for diabetes: rationale and implications of the beta-cell-centric classification schema. Diabetes Care 2016:39:179-86.

4. Heise T, Zijlstra E, Nosek L, Heckermann S, Plum-Morschel L, Forst T. Euglycaemic glucose clamp: what it can and cannot do, and how to do it Diabetes Obes Metab. 2016;18:962-72.

5. Jia W, Weng J, Zhu D, Ji L, Lu J, Zhou Z, et al. Standards of medical care for type 2 diabetes in China 2019. Diabetes Metab Res Rev. 2019;35:e3158.

6. Kim JY, Michaliszyn SF, Nasr A, Lee S, Tfayli H, Hannon T, et al. The shape of the glucose response curve during an oral glucose tolerance test heralds biomarkers of type 2 diabetes risk in obese youth. Diabetes Care. 2016;39:1431-9.

7. Bervoets L, Mewis A, Massa $G$. The shape of the plasma glucose curve during an oral glucose tolerance test as an indicator of Beta cell function and insulin sensitivity in end-pubertal obese girls. Horm Metab Res. 2015;47: 445-51.

8. Herrera-Martinez AD, Enes $P$, Martin-Frias M, Roldan B, Yelmo R, Barrio $R$. The monophasic pattern in oral glucose tolerance test as a predictive risk factor of type 2 diabetes in obese paediatric patients. An Pediatr (Barc). 2017;87:211-7.

9. Kim JY, Coletta DK, Mandarino LJ, Shaibi GQ. Glucose response curve and type 2 diabetes risk in Latino adolescents. Diabetes Care. 2012;35:1925-30.

10. Nolfe G, Spreghini MR, Sforza RW, Morino G, Manco M. Beyond the morphology of the glucose curve following an oral glucose tolerance test in obese youth. Eur J Endocrinol. 2012;166:107-14.

11. Kanauchi M, Kimura K, Kanauchi K, Saito Y. Beta-cell function and insulin sensitivity contribute to the shape of plasma glucose curve during an oral glucose tolerance test in non-diabetic individuals. Int J Clin Pract. 2005;59:427-32.

12. Tschritter O, Fritsche A, Shirkavand F, Machicao F, Haring H, Stumvoll M. Assessing the shape of the glucose curve during an oral glucose tolerance test. Diabetes Care. 2003:26:1026-33.

13. Tura A, Morbiducci U, Sbrignadello S, Winhofer $Y$, Pacini G, Kautzky-Willer A. Shape of glucose, insulin, C-peptide curves during a 3-h oral glucose tolerance test: any relationship with the degree of glucose tolerance? Am J Physiol Regul Integr Comp Physiol. 2011;300:R941-8.

14. Manco M, Nolfe G, Pataky Z, Monti L, Porcellati F, Gabriel R, et al. Shape of the OGTT glucose curve and risk of impaired glucose metabolism in the EGIR-RISC cohort. Metabolism. 2017;70:42-50.

15. Alberti KG, Zimmet PZ. Definition, diagnosis and classification of diabetes mellitus and its complications. Part 1: diagnosis and classification of diabetes mellitus provisional report of a WHO consultation. Diabet Med. 1998;15:539-53.

16. WHO/IDF consultation. Definition and diagnosis of diabetes mellitus and intermediate hyperglycemia.2006. https://www.who.int/diabetes/ publications/Definition\%20and\%20diagnosis\%20of\%20diabetes_new.pdf

17. Ismail HM, Xu P, Libman IM, Becker DJ, Marks JB, Skyler JS, et al. Type 1 diabetes TrialNet study $\mathrm{G}$. the shape of the glucose concentration curve during an oral glucose tolerance test predicts risk for type 1 diabetes. Diabetologia. 2018;61:84-92

18. Matthews DR, Hosker JP, Rudenski AS, Naylor BA, Treacher DF, Turner RC. Homeostasis model assessment: insulin resistance and beta-cell function from fasting plasma glucose and insulin concentrations in man Diabetologia. 1985;28:412-9.

19. Matsuda M, DeFronzo RA. Insulin sensitivity indices obtained from oral glucose tolerance testing: comparison with the euglycemic insulin clamp. Diabetes Care. 1999:22:1462-70.

20. Kosaka K, Hagura R, Kuzuya T, Kuzuya N. Insulin secretory response of diabetics during the period of improvement of glucose tolerance to normal range. Diabetologia. 1974;10:775-82.

21. Retnakaran R, Qi Y, Goran MI, Hamilton JK. Evaluation of proposed oral disposition index measures in relation to the actual disposition index. Diabet Med. 2009;26:1198-203.

22. Abdul-Ghani MA, Lyssenko V, Tuomi T, Defronzo RA, Groop L. The shape of plasma glucose concentration curve during OGTT predicts future risk of type 2 diabetes. Diabetes Metab Res Rev. 2010;26:280-6.

23. Trujillo-Arriaga HM, Roman-Ramos R. Fitting and evaluating the glucose curve during a quasi continuous sampled oral glucose tolerance test. Comput Biol Med. 2008;38:185-95.

24. Arslanian S, El Ghormli L, Young Kim J, Bacha F, Chan C, Ismail HM, et al. The shape of the glucose response curve during an oral glucose tolerance test: forerunner of heightened glycemic failure 
rates and accelerated decline in beta-cell function in TODAY.

Diabetes Care. 2019;42:164-72.

25. Jia W. Diabetes research in China: making progress. Lancet Diabetes Endocrinol. 2017;5:9-10.

26. Cree-Green M, Xie D, Rahat H, Garcia-Reyes Y, Bergman BC, Scherzinger A, et al.

Oral glucose tolerance test glucose peak time is most predictive of

prediabetes and hepatic steatosis in obese girls. J Endocr Soc. 2018;2:547-62.

\section{Publisher's Note}

Springer Nature remains neutral with regard to jurisdictional claims in published maps and institutional affiliations.

Ready to submit your research? Choose BMC and benefit from:

- fast, convenient online submission

- thorough peer review by experienced researchers in your field

- rapid publication on acceptance

- support for research data, including large and complex data types

- gold Open Access which fosters wider collaboration and increased citations

- maximum visibility for your research: over $100 \mathrm{M}$ website views per year

At $\mathrm{BMC}$, research is always in progress.

Learn more biomedcentral.com/submissions 